1 Universidade de São Paulo (USP) - São Paulo (SP), Brasil. Universidade Católica de Salvador (UCSAL) - Salvador (BA), Brasil.

ana.maria.pitta@gmail.com

2 Universidade Federal da Bahia (UFBA) - Salvador (BA), Brasil.

dmcoutinho@uol.com.br

3 Universidade Católica do Salvador (UCSAL) Salvador (BA), Brasil. clarissacmrocha@hotmail. com

\section{Direitos humanos nos Centros de Atenção Psicossocial do Nordeste do Brasil: um estudo avaliativo, tendo como referência o QualityRights - WHO}

\author{
Human rights in Psychosocial Care Centers of Northeast Brazil: an \\ evaluative study with reference to the WHO QualityRights
}

Ana Maria Fernandes Pitta1, Domingos Macedo Coutinho², Clarissa Carvalho Moura Rocha ${ }^{\mathbf{1}}$
RESUMO O artigo pretende avaliar as práticas dos Centros de Atenção Psicossocial no respeito aos direitos humanos dos usuários, analisando suas percepções referentes às crenças, valores, hábitos, preconceitos sofridos, reivindicações atendidas ou não e à participação comunitária, como exercícios de cidadania. Através da análise de dados etno-epidemiológicos do Projeto Avaliar-Caps Nordeste (Ministério da Saúde/2013), utilizando questionários e observação direta, à luz do QualityRights, verificou-se que os Centros de Atenção Psicossocial influenciam positivamente na vida dos usuários, ao estimular-lhes a autonomia, a corresponsabilização no cuidado e o protagonismo sociocultural e político nos serviços e nas suas comunidades.

PALAVRAS-CHAVE Direitos humanos; Saúde mental; Serviços de saúde mental; Avaliação em saúde.

ABSTRACT The article aims to evaluate the practices of Psychosocial Care Centers in respect for human rights of the users, analyzing their perceptions concerning the beliefs, values, habits, prejudices suffered, or not met demands and community participation, as concrete exercise of citizenship. Through the analysis of ethno-epidemiological data of the Project Avaliar-Caps Northeast (Ministry of Health/2013), using questionnaires and direct observation in the light of QualityRights, it was found that the Psychosocial Care Centers positively influence on the lives of the users, by encouraging their autonomy, the co-responsibility in the care and the sociocultural and political leadership in services and in their communities.

KEYWORDS Human rights; Mental health; Mental health services; Health evaluation. 


\section{Introdução}

A partir dos anos 1970 o movimento da Reforma Psiquiátrica Brasileira, cresce, sobretudo, após as Conferências Nacionais de Saúde Mental $(1987,1992,2001,2010)$, a Declaração de Caracas (1992), as portarias ministeriais do Sistema Único de Saúde (SUS) e as leis estaduais e municipais que culminam com a Lei Federal $\mathrm{n}^{0}$ 10.216, de 2001. Os usuários passam a ser vistos como atores/sujeitos do seu próprio tratamento e não mais como meros objetos da violência institucional dos manicômios. Tal fato se explica pela tendência antimanicomial da política de saúde mental oficial, com a redução de leitos psiquiátricos e a simultânea implantação de Centros de Atenção Psicossocial (Caps), que visam prestar diversos tipos de serviços aos usuários, nos territórios, assegurando-lhes direitos socios-sanitários antes não dispensados, estimulando-lhes a autonomia, a corresponsabilização no cuidado e no protagonismo sociocultural e político. Tanto é assim, que se caracterizam como missões dos Caps:

Prestar atendimento clínico em regime de atenção diária, evitando as internações em hospitais psiquiátricos; acolher e atender as pessoas com transtornos mentais graves e persistentes, procurando preservar e fortalecer os laços sociais do usuário em seu território; promover a inserção social das pessoas com transtornos mentais por meio de ações intersetoriais; regular a porta de entrada da rede de assistência em saúde mental na sua área de atuação; dar suporte à atenção à saúde mental na rede básica; organizar a rede de atenção às pessoas com transtornos mentais nos municípios; articular estrategicamente a rede e a política de saúde mental num determinado território; promover a reinserção social do indivíduo através do acesso ao trabalho, lazer, exercício dos direitos civis e fortalecimento dos laços familiares e comunitários. (BRASIL, 2004).
Fica claro que essa nova organização da assistência à saúde mental no País, de um lado, busca garantir o acesso ao tratamento na sua comunidade de referência, através do cuidado clínico, do uso racional de psicofármacos e programas de reabilitação psicossocial, objetivando enfrentar a experiência psicopatológica e a marginalização, além da exclusão social dos usuários. Tudo isto passa a compor as diretrizes básicas do modelo de atenção. Por outro lado, a sua implantação e o desenvolvimento de ações demandam uma radicalização ética capaz de modificar as organizações de serviços, os níveis de complexidade tecnológica do sistema de saúde, as estratégias de racionalização dos custos e a reorientação da demanda, que ainda não conseguimos alcançar.

Dados da Organização Mundial da Saúde (OMS) estimam que, no mundo, uma em cada quatro pessoas sofre com transtornos mentais, o que significa que, no Brasil, cerca de 47.500.000 pessoas sofrem ou sofrerão, ao longo de suas vidas, algum tipo de transtorno mental, representando $12 \%$ da carga global de doenças (WHO, 2001). Na região Nordeste, os estados da Bahia, de Sergipe, de Pernambuco, de Alagoas e da Paraíba contam com uma população estimada em 32 milhões de pessoas. No limite, poderiam existir ali cerca de 3,5 milhões de pessoas com transtornos mentais e transtornos decorrentes de usos de substâncias psicoativas.

Apesar dessa importante magnitude epidemiológica, o estigma que cerca historicamente os transtornos mentais e o uso de substâncias psicoativas nas sociedades faz com que se invista pouco na promoção do cuidado e do tratamento, e que se respeitem, menos ainda, os direitos dessas pessoas. Desta forma, apenas uma minoria da população consegue acesso ao cuidado de que necessita, e as instituições hospitalares que prestam esses cuidados têm se caracterizado, em sua maioria, pela violação dos direitos humanos dessa população e pela baixa eficácia reabilitadora. 
No enfrentamento dessa realidade e visando melhorar a qualidade e as condições de respeito aos direitos humanos em instituições psiquiátricas e de saúde mental, manicômios judiciários e serviços de assistência social, a OMS desenvolveu o projeto QualityRights, para capacitar os próprios usuários e organizações da sociedade civil na defesa dos direitos das pessoas com transtornos mentais e psicossociais (WHO, 2012).

$\mathrm{O}$ projeto caracteriza-se por um conjunto de propostas/ações/programas que defendem os direitos das pessoas com transtornos mentais em diferentes países do mundo, incluindo o Brasil. Um grupo tarefa internacional construiu um kit de ferramentas de garantia de qualidade de serviços e direitos humanos dos usuários para ser utilizado, tanto em países de baixa, quanto de média e alta renda. Oficialmente lançado em 28 de junho de 2012, na cidade de Nova York (Estados Unidos), foi discutido e pactuado por entidades governamentais de muitos países, em sua forma de utilização e implementação. A força do QualityRights reside na sua capacidade de avaliar e estimular melhorias dos serviços na ponta, tanto na sua execução, quanto no plano político de conquistas de direitos. Ele analisa a qualidade da assistência e dos direitos humanos em serviços comunitários e hospitalares através de uma abordagem participativa, envolvendo técnica e eticamente pessoas com problemas de saúde mental ou em uso de substâncias psicoativas, seus familiares, profissionais de saúde e gestores. O programa tem como principal benefício pôr fim às violações que acontecem em toda a gama de instalações de saúde mental e de assistência social, e melhorar a qualidade do apoio e dos cuidados prestados, proporcionando formação e desenvolvimento de habilidades para os profissionais de saúde e para as pessoas com transtorno mental que estão em tratamento. Sua implementação tem como objetivo levar uma série de mudanças positivas ao interior dos serviços de saúde e assistência social, que incluem: a criação de condições de vida segura e saudável em instalações e ambiente favorável à recuperação; a implementação de cuidados baseados em evidências para problemas de saúde físico-mental; com base no consentimento livre e esclarecido, em vez de coerção, a prática de tratamentos que aumentem a autonomia das pessoas para se engajar em seus planos de recuperação (recovery), onde a participação do usuário como condutor dos tratamentos é a tônica; melhor suporte para ajudar as pessoas a encontrar habitação, trabalho, educação e acesso a benefícios e serviços sociais; e, finalmente, colocar um fim nas práticas de tratamento desumanas e degradantes observadas nas instituições sanitárias e sociais, práticas essas tão difundidas em todo o mundo. Objetiva, ainda, a capacitação dos usuários do serviço, bem como de familiares e profissionais de saúde, para compreender e promover os direitos humanos e a recuperação em transtornos mentais e abuso de substâncias, desenvolvendo um movimento, na sociedade civil, das pessoas com transtorno mental, para prestar apoio mútuo, advogar e influenciar as decisões políticas de acordo com as normas internacionais de direitos humanos e reformar as políticas e legislações nacionais, em consonância com as melhores práticas de tratamento nos padrões internacionais de pleno respeito aos direitos humanos.

É importante ressaltar que QualityRights é um movimento da sociedade civil capitaneado pela OMS, que advoga que usuários de instituições psiquiátricas e de saúde mental possam participar mais plenamente da vida da comunidade, ter acesso a oportunidades de educação e emprego, contribuir ativamente para processos de decisão sobre as questões que os afetam, e trabalhar para a prestação de serviços de qualidade em saúde mental nas comunidades onde vivem.

O Projeto Avaliar-Caps, por sua vez, traz uma prescrição inicial do Ministério da Saúde, referindo-se à utilização dos recursos para as 
ações de caráter operacional e aplicado, que visam encontrar soluções para resolver os problemas que limitam a efetividade da saúde e para desenvolver métodos e técnicas que ampliem a capacidade de intervenção nos problemas de saúde. Como justificativa para a sua realização na região Nordeste teria: a que mais cresceu nos últimos anos e, por isso mesmo, necessita ações de fomento, pesquisa, capacitação e incremento da rede, em plena concordância com a reforma psiquiátrica brasileira, particularmente a partir do advento da Lei ${ }^{\circ}$ 10.216/2001 (BRASIL; ET AL., 2011). Neste sentido, as ações, os objetivos e as metas aqui propostos pretendem não só incrementar e qualificar a rede de Caps, como avaliar a função do dispositivo Caps na rede de cuidados de saúde mental e uso prejudicial de substâncias psicoativas, em especial o crack. Buscava ainda,

desenvolver pesquisas, avaliação e qualificação da rede de saúde mental, álcool e outras drogas através do planejamento de cursos (extensão, aperfeiçoamento e especialização) dos atores envolvidos na área (profissionais, usuários e familiares), pesquisas de avaliação (de serviços e de atores), realização de atividades de divulgação (congressos, seminários, palestras etc.) e publicações (livros, folhetos, vídeos etc.). (BRASIL; ET AL., 2011).

A opção por colocar os direitos humanos como foco dessa avaliação foi uma proposta da equipe Universidade Federal da Bahia/ Universidade Católica do Salvador (UFBA/ UCSAL), pactuada pelos parceiros(as) e colaboradores(as), buscando responder à seguinte questão: Os direitos humanos fundamentais de usuários, familiares e profissionais estariam sendo respeitados nas práticas cotidianas dos Centros de Atenção Psicossocial?

\section{Objetivos}

O artigo objetiva avaliar as práticas dos Centros de Atenção Psicossocial em relação ao respeito aos direitos dos usuários, destacando-se: o respeito às crenças, valores e hábitos; a realização de atividades que reduzam o preconceito contra a loucura e o uso de drogas; a existência e a participação em assembleias nos Caps como exercício de cidadania; e, a atenção, o respeito e as devidas respostas às reivindicações feitas pelos usuários.

\section{Percurso metodológico}

O artigo utilizou dados parciais do Projeto Avaliar-Caps Nordeste (2013), que aconteceu em duas fases: Fase I - Conhecer para avaliar: utiliza um questionário estruturado, que, por via eletrônica, busca alcançar um censo epidemiológico de todos os Caps existentes nos cinco estados abrangidos: Bahia, Sergipe, Alagoas, Pernambuco e Paraíba, para conhecer suas características de estrutura, processo e resultados. Já a Fase II - Estudo etno-epidemiológico de avaliação da humanização e efetividade dos Caps: consistiu em observações diretas de cinco Caps, de cada região metropolitana, nos cinco estados estudados, e a aplicação de instrumento etno-epidemiológico construído para tal fim, para cinco usuários, cinco familiares e cinco profissionais, em cada Caps estudado nessa fase.

Utilizou-se uma sub-amostra por conveniência de 75 entrevistados em cada estado, com questionários e também roteiros de observação direta, produzidos à luz do QualityRights (WHO, 2012), para cada Caps estudado nessa fase, através dos quais se indagou especificamente sobre o respeito às crenças, valores e hábitos; a realização de atividades que reduzam o preconceito; a participação em assembleias; e, o atendimento e as devidas respostas às reivindicações feitas pelos usuários. Já havia sido iniciada tal avaliação quando, em julho de 2012, foi lançado, em Nova York, o WHO QualityRights, com objetivos comuns ao estudo aqui desenvolvido. A comparação de instrumentos já construídos com as ferramentas do QualityRights 
revela inúmeros pontos de identidade entre as duas iniciativas. Desde então, se considerou o estudo afinado ao Movimento QualityRights - WHO, que se constitui em uma estratégia potente de avaliação e enfrentamento do estigma, da qual tais usuários podem participar e se beneficiar.

A abordagem QualityRights aplicada na pesquisa avaliativa desenvolvida concentra-se na observação direta de oito dimensões, nos Caps escolhidos: a primeira dimensão observa Estrutura Física, Acessibilidade e Ambiência, com pontos de análise sobre limpeza, segurança, conforto, disponibilidade de espaços e barreiras de acesso, verificadas também pelos questionários qualitativos, particularmente nas dimensões de livre circulação, de respeito à privacidade dos usuários. A segunda dimensão concentra-se nas Atividades, analisando a admissão, o acolhimento, a identificação e a distribuição das atividades em grupo realizadas em diferentes formas, tangenciando a presença da 'interdisciplinaridade' no trabalho das equipes. A terceira dimensão corresponde ao Projeto Terapêutico Singular, com observações sobre formas de elaboração, execução, participação dos usuários e familiares, sendo feitas perguntas acerca dos aspectos da vida fora do Caps (moradia, renda, trabalho, vínculos sociais, família, lazer etc.). A quarta dimensão analisa a Articulação em Rede, com observações diretas e questionários sobre integração no espaço territorial, apoio municipal e/ou estadual, parceiros e identificação dos obstáculos. Na quinta dimensão estão os Familiares e a Rede Social, com observações sobre o envolvimento dos familiares e membros da rede social potencial dos usuários. A sexta dimensão corresponde aos Medicamentos, com algumas questões sobre a disponibilidade destes, segundo usuários, familiares e profissionais. Não está colocada a avaliação da eficiência dos medicamentos, pois isto necessitaria de outros recursos não priorizados na atual avaliação. Na sétima dimensão está a Alimentação, da qual se depreende, nas observações diretas, que este fator parece ser muito importante para o padrão de vida dos usuários. Por fim, temos, na oitava dimensão, o estudo das Relações Interpessoais, onde se verifica a qualidade da comunicação da equipe entre si e com os usuários e familiares, pelas visitas nos Caps e pela análise das discussões de casos nas reuniões técnicas observadas, com avaliações positivas ou negativas referentes às perguntas feitas a usuários, familiares e profissionais, nos questionários.

\section{Resultados}

Foram analisadas informações relativas à garantia dos direitos do usuário e sua cidadania, nos questionários respondidos através da análise das percepções de usuários, referentes às suas crenças, valores, hábitos, preconceitos, reivindicações e participação comunitária, e ao respeito à dignidade no acompanhamento das ações desenvolvidas nos Caps dos cinco estados estudados.

\section{Bahia}

No que se refere à garantia de direitos humanos, exercitada nas práticas cotidianas, $88 \%$ dos usuários sentiram-se respeitados nas suas crenças, valores e hábitos; 83,33\% referiram que o Caps realiza trabalhos para diminuir o preconceito contra a loucura e os transtornos decorrentes do uso de substâncias. Ainda, $40 \%$ disseram ter feito reivindicações e solicitações ao serviço. Dentre estes, $44,4 \%$ obtiveram respostas positivas às tais reivindicações, e somente $44 \%$ dos usuários referiram participar de assembleias nos Caps (gráfico 1). 
Gráfico 1. Garantia de direitos humanos (crenças, valores, hábitos, preconceito, reivindicações e participação comunitária) de usuários. Bahia, 2013

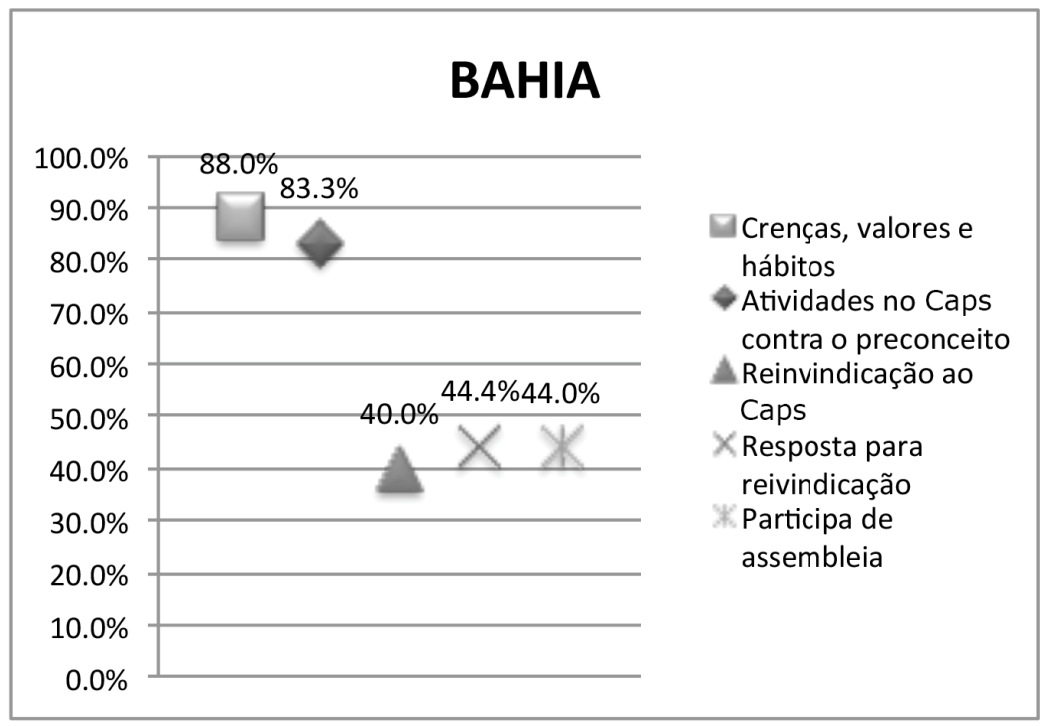

Nota: Elaboração própria

\section{Sergipe}

No estado de Sergipe, quanto ao respeito às crenças, valores e hábitos, $83 \%$ dos usuários afirmaram ter sido respeitados; $79 \%$ disseram que o Caps faz atividades para diminuir o preconceito. Dos usuários, $65 \%$ já fizeram reivindicações/solicitações para o Caps; e $66,7 \%$ obtiveram respostas para suas reivindicações. Ainda, $61 \%$ dos usuários participaram de assembleias no Caps (gráfico 2).

Gráfico 2. Garantia de direitos humanos (crenças, valores, hábitos, preconceito, reivindicações e participação comunitária) de usuários. Sergipe, 2013

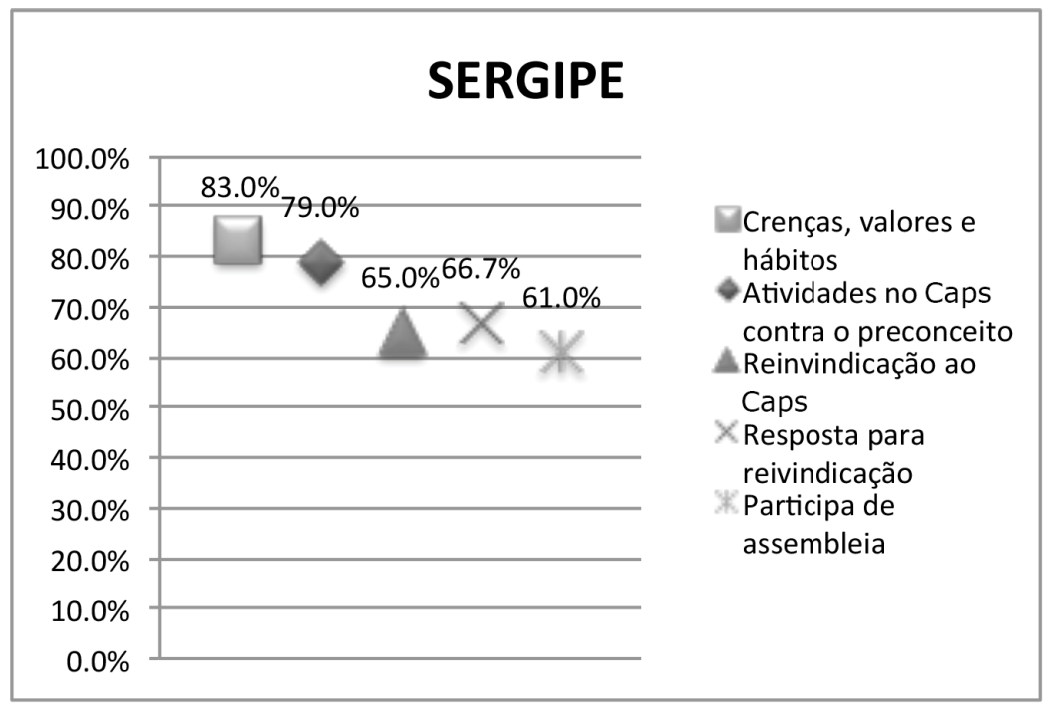

Nota: Elaboração própria 


\section{Alagoas}

Verifica-se que no estado de Alagoas, $88 \%$ referiram que a equipe tratou com respeito as crenças, valores e hábitos dos usuários; $95,7 \%$ afirmaram que os Caps promovem atividades para diminuir o preconceito; $48 \%$ já fizeram reivindicações/solicitações, das quais $46,2 \%$ obtiveram respostas; e $56 \%$ desses usuários afirmaram não participar de assembleias (gráfico 3).

Gráfico 3. Garantia de direitos humanos (crenças, valores, hábitos, preconceito, reivindicações e participação comunitária) de usuários. Alagoas, 2013

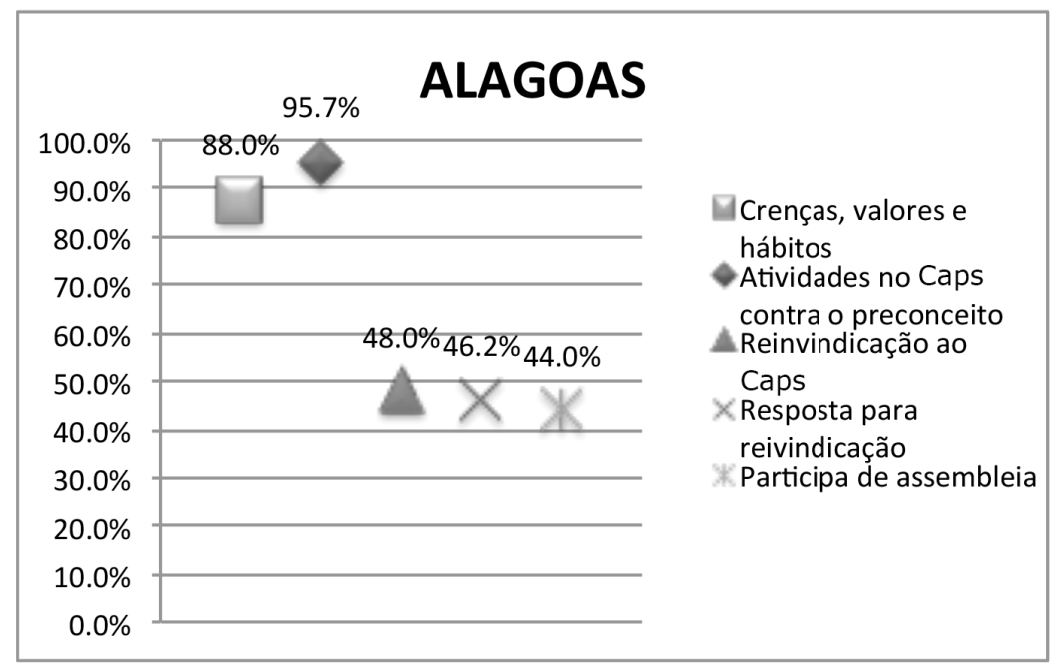

Nota: Elaboração própria

\section{Pernambuco}

No estado de Pernambuco, 86,4\% dos usuários afirmaram que o Caps faz atividades para diminuir o preconceito e $52 \%$ já fizeram reivindicações/solicitações para o Caps, das quais $61,5 \%$ obtiveram respostas às mesmas.
Ademais, $60 \%$ participaram de assembleia no Caps. Procurou-se saber a percepção de usuários quanto ao fato de ser tratado com respeito e dignidade, e, predominantemente, os usuários se sentiram satisfeitos $(80 \%)$ quanto ao respeito às crenças, valores e hábitos (gráfico 4). 
Gráfico 4. Garantia de direitos humanos (crenças, valores, hábitos, preconceito, reivindicações e participação comunitária) de usuários. Pernambuco, 2013

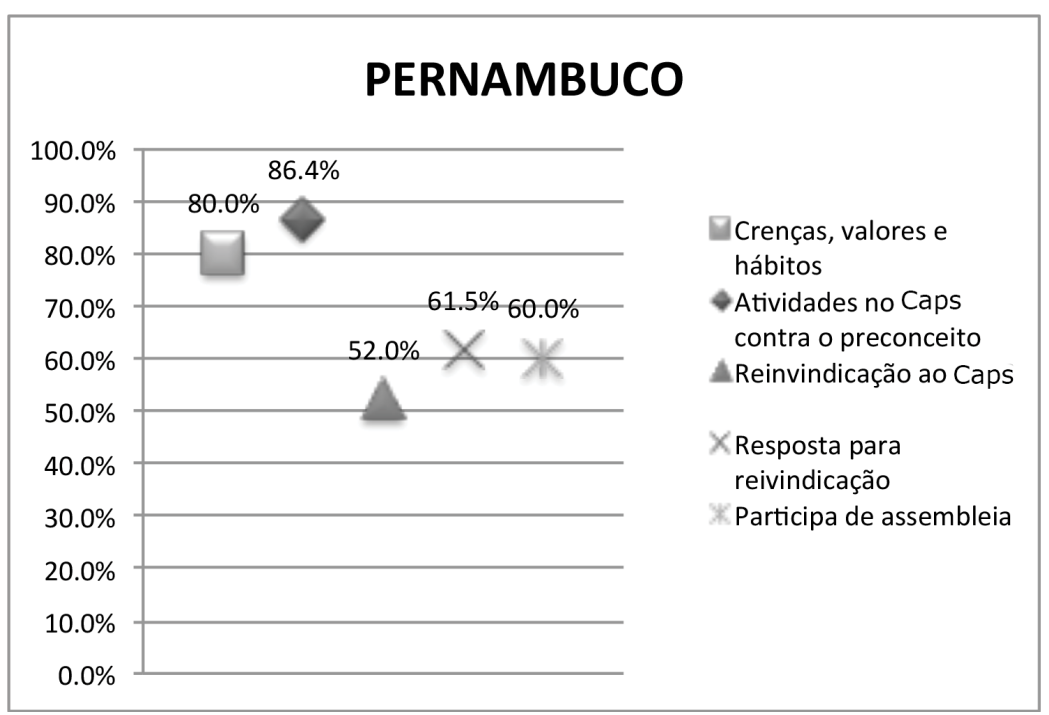

Nota: Elaboração própria

\section{Paraíba}

Também na Paraíba foram selecionadas cinco categorias para avaliarmos o respeito aos direitos humanos e ao exercício de cidadania e autonomia dos usuários. Dentre os usuários, $80 \%$ afirmaram que os Caps promovem atividades para diminuir o preconceito; apenas $36 \%$ já fizeram reivindicações/solicitações, dos quais $53,9 \%$ obtiveram resposta; e $80 \%$ dos mesmos afirmaram participar de assembleias. Uma cultura de valorização de direitos humanos e participação de usuários se faz presente na localidade (gráfico 5).

Gráfico 5. Garantia de direitos humanos (crenças, valores, hábitos, preconceito, reivindicações e participação comunitária) de usuários. Paraíba, 2013

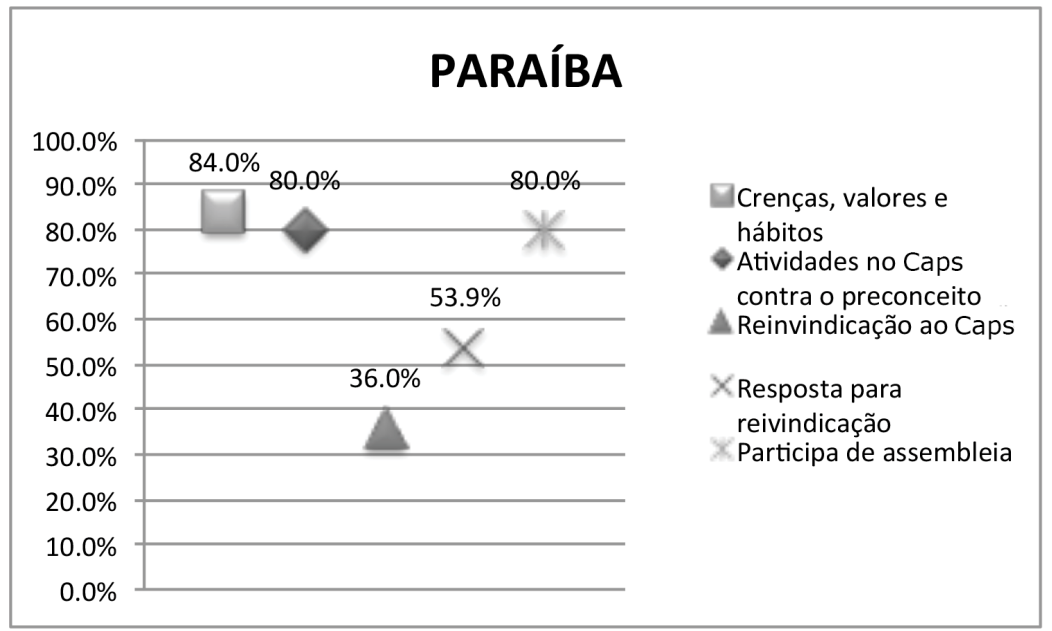

Nota: Elaboração própria 


\section{Discussão}

Embora tenha havido variabilidade entre os estados, e alguns tenham alcançado melhores escores no exercício de cidadania do usuário, nos aspectos selecionados do estudo, o que pode refletir indicativos de gestão estadual e/ou municipal mais comprometidas com a democracia nos serviços em alguns locais, temos ainda poucos elementos para isto afirmar. Nestas últimas décadas regidas pela Constituição Cidadã de 1988, que marca o ordenamento jurídico-político brasileiro com uma nova visão democrática, temos assistido a uma progressiva institucionalização e luta por direitos humanos no País. A Carta Magna torna essenciais a cidadania e a dignidade da pessoa humana, elegendo os direitos e as garantias individuais e coletivas como núcleo intocável da Constituição. Acerca do binômio democracia e direito do homem, "o reconhecimento e a proteção dos direitos do homem estão na base das Constituições democráticas modernas", uma vez que "sem direitos do homem reconhecidos e protegidos, não há democracia" (BOBBIO, 2004, P. 93) .

Não obstante, a Carta de 1988 inova ao não mais se limitar a assegurar apenas direitos individuais, alargando a dimensão dos direitos e garantias, e tutelando os direitos coletivos e difusos, isto é, aqueles pertinentes à determinada classe ou categoria social, e estes a todos e a cada um, o que a classifica como uma Constituição Social. Atente-se ao fato de que, no intuito de reforçar a imperatividade das normas que traduzem direitos e garantias fundamentais, foi instituído também no texto de 1988 o princípio da aplicabilidade imediata das normas definidoras de direitos e garantias fundamentais (PIOVESAN, 2013). Neste sentido, os direitos sociais, como dimensão dos direitos fundamentais do homem, são ações positivas proporcionadas pelo Estado, direta ou indiretamente, enunciadas em normas constitucionais, que possibilitam melhores condições de vida aos que mais necessitam, que tendem a realizar a igualização de direitos em situações sociais desiguais. Tem-se, assim, a disposição de atender igualmente o direito de cada um como uma adequada definição de equidade imprescindível para se pensar direitos e cidadania para os 'diferentes' e 'para todos'.

É neste contexto que se inicia a preocupação com a cidadania para os 'doentes mentais' e 'drogaditos'. Ao prestar o direito à saúde e assistência social a quem dela necessita, com o objetivo de habilitar e reabilitar as pessoas em desvantagem psicossocial e promover sua integração à vida comunitária, o Estado brasileiro se propõe a assegurar o bem estar social de todos os indivíduos, iguais e diferentes (PITTA, 1992). É nesse espírito que a Lei ${ }^{\circ}$ 10.216/2001, amplamente debatida ao longo de 12 anos, até sua homologação, traz para a Reforma Psiquiátrica Brasileira o marco legal que promove a cidadania 'dos loucos' em uma 'sociedade sem manicômios', como a regra legalmente prescrevera.

Assim, instituem-se serviços substitutivos, tipo Caps, que são implantados segundo as decisões das políticas municipais e estaduais, e de acordo com critérios populacionais (Caps I, Caps II e Caps III) e grupos de risco, tais como crianças/adolescentes e usuários de álcool e drogas, respectivamente Centros de Atenção Psicossocial Infantojuvenil (Capsi) e Centros de Atenção Psicossocial Álcool e Drogas (Capsad).

Quando da aplicação dos questionários e das observações diretas realizadas, estávamos no período eleitoral e muitos foram os serviços desativados, com coordenadores demitidos aguardando as novas gestões para se recomporem. A sazonalidade dos Caps é um lamentável fato, que impõe um esforço de estruturação e formalização institucional para se tornar um serviço 'forte' e permanente, capaz de acolher e cuidar das demandas complexas de sua clientela, que não desaparecem a cada eleição.

De acordo com a série histórica de implantação dos Caps no Brasil, o Nordeste é a segunda região com maior índice de 
cobertura no País, perdendo apenas para a região Sul. Na região, se destaca o estado da Paraíba, com o maior índice de cobertura assistencial brasileira (1,5 Caps/100.000 hab.), seguido de Sergipe, com a segunda maior cobertura assistencial do País (1,28 Caps/100.000 hab.). A partir da análise dos 75 questionários aplicados, foram geradas informações sobre a percepção dos usuários nos cinco estados da região Nordeste estudados. Acerca da garantia dos direitos humanos e exercícios de cidadania ativa, verificou-se que os Caps influenciam positivamente a vida dos usuários, assegurando-lhes atividades que reduzem o preconceito, incentivam a participação em assembleias, estimulam e respondem às suas reivindicações e realizam tratamentos com base no respeito e na dignidade. Incluir a participação dos usuários na gestão de serviços é um reconhecimento dos seus direitos na instituição. O estigma traz, sem a menor dúvida, um peso importante na inclusão atual dos usuários do sistema na sociedade, e ter ações para coibir o preconceito é advogar em favor desses usuários do sistema.

Neste sentindo, partindo da premissa de que ser cidadão é ser um indivíduo dotado de direitos que lhe permitem não só se defrontar com o Estado, mas afrontar o Estado, através do exercício pleno e do conhecimento de direitos, bem como a capacidade de reivindicar, caso esses direitos não estejam sendo respeitados, podemos dizer que os indivíduos com transtornos mentais e usuários de álcool e outras drogas estão se tornando sujeitos e atores das suas próprias vidas.

Contudo, o conceito contemporâneo de cidadania, que compreende a indivisibilidade e a interdependência entre os direitos humanos, caminha em constante tensão com as ideias de liberdade, de justiça política, social e econômica, de igualdade de chances e de solidariedade a que se vinculam, ocupando um papel central na construção do Estado Democrático de Direito (TORRES, 2001). É preciso ter consciência de que, apesar de estar consolidado na democracia brasileira, o princípio da igualdade (todos são iguais perante a lei), é necessária a relativização do mesmo, já que precisamos respeitar as individualidades de cada um, tratando os iguais igualmente e os desiguais desigualmente. Por outro lado, surge, a partir de julgados do Tribunal Constitucional Federal da Alemanha, a Teoria da Reserva do Possível, que foi rapidamente absorvida pelos governos brasileiros, colocando-se em questão a suficiência de recursos públicos para a implementação das ações exigidas do Estado, por lei e por grupos de interesses, como os enfermos mentais ou usuários de drogas. Torna-se uma restrição fática aplicável pelos governos de municípios, estados e união para se recusarem a dotar os territórios dos dispositivos adequados à garantia desses direitos fundamentais, admitindo que o Estado poderá não atender às postulações de direitos sociais, se estiver diante de uma escassez de recursos capaz de restringir a sua atuação e, por consequência, a própria concretização desses direitos (MOREIRA, 2011).

Desta forma, como garantir a concretização dos direitos sociais em um contexto com tanta iniquidade? Como se dá a inserção social àqueles a quem se atribui um transtorno mental num país com baixa magnitude de gastos sociais e de saúde, que assiste a um importante movimento de minimização da atuação do Estado em relação aos compromissos sociais com a sociedade? Em uma sociedade neoliberal, quais os direitos que estão compondo o exercício de cidadania dos usuários de serviços de saúde mental, como um Caps? A crise da cidadania no Brasil pode ser percebida, quer seja devido à ausência de atenção aos direitos humanos pela maior parte da sociedade, quer seja em razão de seu baixo grau de solidariedade orgânica, expresso nos ainda frágeis movimentos sociais (GUERRA, 2012).

Em um país com desigualdades acentuadas, a cidadania e a qualidade de vida da população constituem um desafio e uma 
questão social, na medida em que esse binômio é representado por um contexto de dimensões variadas, no qual se incluem percepções, experiências de vida e oportunidades sociais, além de recursos socio-culturais e econômicos, que se refletem no acesso à educação, saúde, transporte e habitação, entre outros.

\section{Conclusões e limitações do estudo}

Os limites já acontecem na implantação e na sustentação dos Caps, na quantidade e na qualidade dos serviços prestados para uma cobertura assistencial adequada, embora se tenha expandido a rede de serviços na região. Um modelo contra hegemônico de base territorial em um país de forte tradição manicomial e poderio do capital real e simbólico vinculado às práticas manicomiais no cuidado da loucura e suas derivações (lugar de louco é no asilo), reforça seu estatuto de vulnerabilidade. Avança-se e recua-se a cada mudança política sazonal, a cada eleição. O Nordeste do Brasil tem especificidades sociais e culturais que somente agravam os problemas de implantação e gestão de serviços que possam estar a favor da democracia e do pleno respeito a direitos humanos fundamentais de usuários e familiares. Estratégias metodológicas inovadoras, que capturem a complexidade das suas práticas, repercutindo em conquistas reais na qualidade de vida dos usuários e nas relações dos seus vários atores foram dimensões buscadas no estudo. Entretanto, ainda se percebe a necessidade de incorporação de instrumentos que possam mais apropriadamente captar a sua realidade, possibilitando a criação de indicadores aceitos pelos governos e que, simultaneamente, tragam contribuições para a gestão desses serviços, ao mesmo tempo em que propiciem o desenvolvimento de práticas mais inclusivas e participativas para os usuários, e que contribuam nos seus restabelecimentos para uma vida digna, em liberdade.

Pode-se inferir que, dos avanços alcançados pelos usuários do sistema nessa transição de modelo assistencial do manicômio à comunidade, o direito humano de ir e vir, de ser escutado nas suas diversas linguagens, de ser reconhecido nas suas experiências intersubjetivas de identidades e alteridades, considerando suas crenças, valores e hábitos, e uma ética de solidariedade cidadã no enfrentamento do preconceito e nas barreiras da exclusão são evidências que se constatam no estudo, nas quais é preciso avançar e, se espera, que sejam irreversíveis.

\section{Referências}

BOBBIO, N. A Era dos Direitos. Rio de Janeiro: Elsevier, 2004.

BRASIL. Lei $n^{o}$ 10.216, de 06 de Abril de 2001. Dispõe sobre a proteção e os direitos das pessoas portadoras de transtornos mentais e redireciona o modelo assistencial em saúde mental. Brasília, DF. Disponível em: <http:// www.planalto.gov.br/ccivil_03/leis/leis_2001/110216. htm>. Acesso em: 4 mar. 2014.
BRASIL. Ministério da Saúde et al. Termo de Referência do Projeto Avaliar Caps- Nordeste. 2011. Mimeo.

BRASIL. Ministério da Saúde. Secretaria de Atenção à Saúde. Departamento de Ações Programáticas Estratégicas. Saúde mental no SUS: os centros de atenção psicossocial. Brasília, DF: Ministério da Saúde, 2004. Disponível em: <http://www.ccs.saude.gov.br/saude mental/pdf/sm_sus.pdf >. Acesso em: 3 set. 2013. 
DECLARAÇÃO DE CARACAS. In: UZACÁTEQUI,

R. G.; LEVAV, I. (Ed.). Reestruturação da assistência

psiquiátrica: bases conceituais e caminhos para a sua implementação. Washington, DC: Organização Pan-

Americana da Saúde. 1991. p. 1-3.

GUERRA, S. Direitos humanos \& cidadania. São Paulo: Atlas, 2012

MOREIRA, A. As restrições em torno da reserva do possível: uma análise crítica. Belo Horizonte: Fórum, 2011.

PIOVESAN, F. Temas de Direitos Humanos. São Paulo: Saraiva, 2013.

PITTA, A. M. F. Avaliação como Processo de Melhoria na Qualidade de Serviços Públicos de Saúde. Revista de Administração Pública, Rio de Janeiro, v. 26, n. 2, p. 44- 61, 1992.

Um balanço da reforma psiquiátrica brasileira: instituições, atores e políticas. Ciência e saúde coletiva, Rio de Janeiro, v. 16, n. 12, p. 4579-4589. 2011.

PITTA, A. M. F. et al. Avaliação da qualidade do cuidado em Centros de Atenção Psicossocial: Estados da Bahia, Sergipe, Alagoas, Pernambuco e Paraíba no Nordeste do Brasil - AVALIAR-Caps NORDESTE - Relatório Técnico, Salvador, Bahia, jun. 2013.
PITTA, A. M. F.; GOLDBERG, J. I. El Centro de Atenção Psicosocial: Un Modelo de Atencion de Pacientes en la Comunidad. Organización Panamericana de Salud, v. 2, p. $50-83,1994$.

SANTOS, M. As cidadanias mutiladas. São Paulo: IMESP, 1996-1997, p. 133-144.

SARACENO, B.; BERTOLOTE, J. M. Avaliação dos serviços psiquiátricos: indicadores duros e macios. In: ORGANIZAÇÃO MUNDIAL DA SAÚDE (Org.) Abordagens inovadoras na avaliação do serviço. Genebra (Suíça): Organização Mundial da Saúde, 1993. p. 1-48.

TORRES, R. L. A cidadania multidimensional da era dos direitos. Teoria dos direitos fundamentais. Rio de Janeiro: Renovar, 2001, p. 256.

\section{WORLD HEALTH ORGANIZATION (WHO). WHO} QualityRights tool kit to assess and improve quality and human rights in mental health and social care facilities. Geneva: WHO, 2012.

\footnotetext{
Recebido para publicação em setembro de 2014

Versão final em novembro de 2014

Conflito de interesses: inexistente

Suporte financeiro: Ministério da Saúde do Brasil - FAPEX.

Processo no 110007.04
} 